\title{
Restauración de parcela degradada mediante aplicación de material bioestabilizado y cultivos energéticos en Júndiz (Vitoria-Gasteiz)
}

\author{
Hidalgo Castañeda, J.', Garbisu Crespo, C. ${ }^{2}$, Becerril Soto, J.M.', \\ Artetxe Aspiunza, U. ${ }^{3}$ y Vilela Lozano, J. ${ }^{*}$ \\ ${ }^{2}$ Ayuntamiento de Vitoria-Gasteiz-Vitoria-Gasteizko Udala. Pintor Teodoro Doublang 25, 01008, Vitoria-Gasteiz. \\ ${ }^{2}$ NEIKER Instituto Vasco de Investigación y Desarrollo Agrario. Bizkaiko Parke Teknologikoa, 812., 48160, Derio. \\ ${ }^{3}$ Universidad del País Vasco-Euskal Herriko Unibertsitatea, Facultad de Ciencia y Tecnología, 48080, Bilbao \\ •Autor para correspondencia: jvilela@vitoria-gasteiz.org
}

\section{Resumen}

En las últimas décadas se ha producido una alarmante disminución de la calidad de los suelos a nivel global debido principalmente a la erosión, contaminación y salinización (FAO, 2011). Además, el crecimiento urbano en muchas ciudades ha significado también su degradación, por su sellado o por acumulación de residuos. La degradación del suelo, según la FAO, es un cambio en la salud del suelo resultando en una disminución de la capacidad del ecosistema para producir bienes o prestar servicios. En Vitoria-Gasteiz, la intensa urbanización ocurrida en los últimos años, ha generado un gran número de parcelas vacantes que permanecerán décadas sin edificar, corriendo el riesgo de degradarse por usos indebidos o acumulación de vertidos. El Ayuntamiento de Vitoria-Gasteiz ha impulsado varias líneas para mejorar esta situación. Entre otras alternativas, la mejora producida en las plantas de gestión de residuos municipales ofrece oportunidades para la reutilización de sus subproductos en la restauración de zonas degradadas. La valorización de residuos, entendidos de este modo como un recurso, constituye un objetivo fundamental del Plan de Prevención y Gestión de Residuos de la CAPV 2020. El proyecto piloto de restauración de suelos degradados en Jundiz propone realizar un ensayo en 1 ha de terreno público mediante la aplicación de "material bioestabilizado" (MB) procedente de la planta de tratamiento de RSU's "Biocompost de Álava" y una rotación de cultivos agrícolas para uso energético.

Palabras clave: Colza, Residuo, Regeneración, Suelo. 


\section{Introducción}

\subsection{Problemática}

La reciente e intensa urbanización desarrollada en el entorno de Vitoria-Gasteiz, unida a la crisis inmobiliaria, ha complicado gravemente la gestión del suelo municipal. Numerosas parcelas municipales (Fig. 1) y privadas permanecen sin edificar y corren riesgo de degradarse por acumulación de escombros o vertidos. En un estudio realizado en 2013 por el Centro de Estudios Ambientales (CEA) de Vitoria-Gasteiz se contabilizaron hasta 215 parcelas municipales vacantes en riesgo de degradación, derivando en un considerable coste de mantenimiento así como en una reducción de la calidad paisajística.

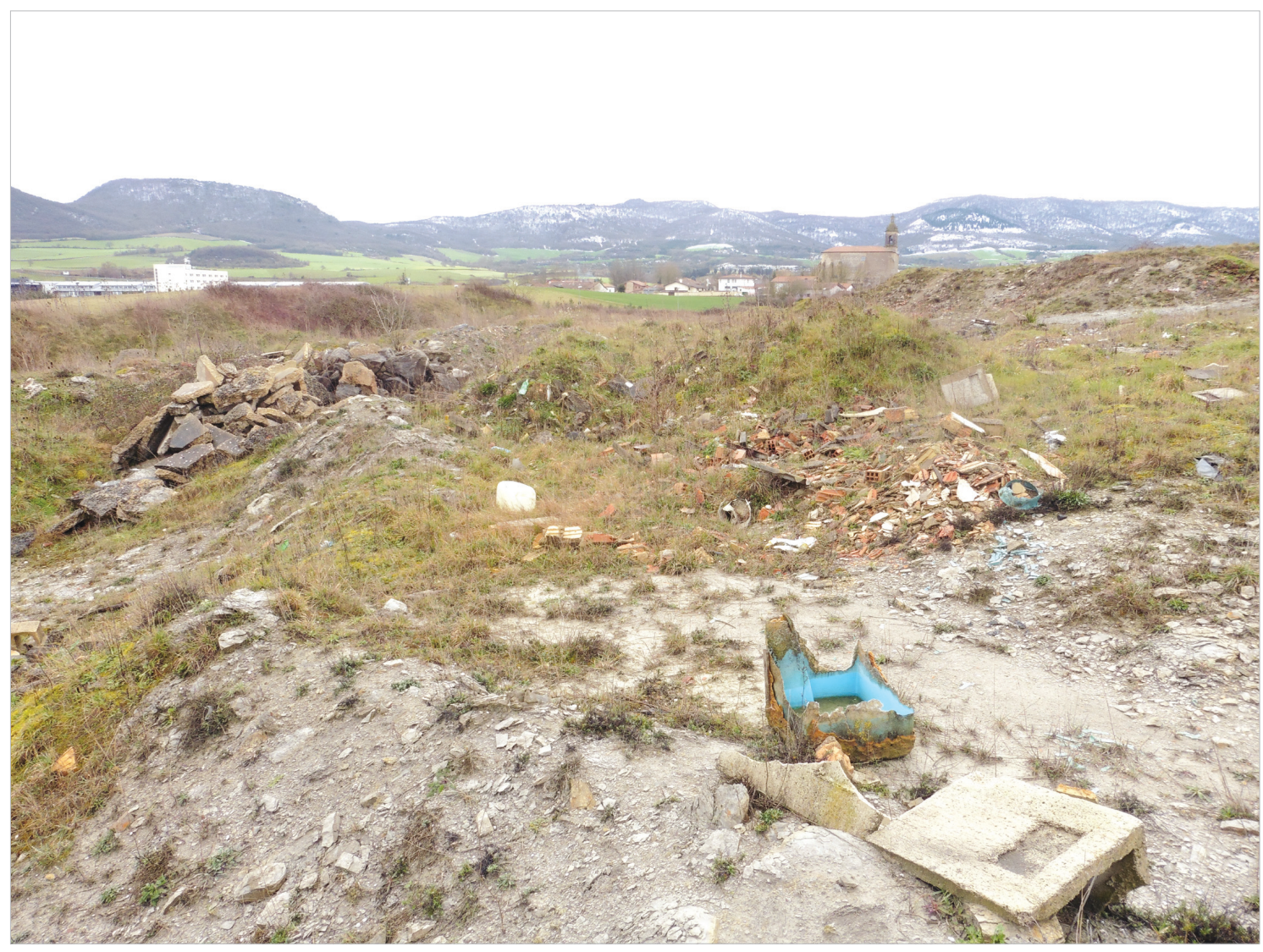

Figura 1. Parcela municipal degradada en el polígono de Jundiz próxima al pueblo de Aríñez (T.M de Vitoria-Gasteiz). Foto: 24/02/2016

Por otro lado, la planta provincial de tratamiento de residuos sólidos urbanos (RSU) "Biocompost de Álava" ha mejorado notablemente su gestión en los últimos años, reduciendo en gran medida el volumen de residuos del vertedero. Ello permite que parte de los subproductos resultantes tengan suficiente calidad como para ser reutilizados, pero aquellos sobre los que no existe todavía una demanda comercial 
o una regulación clara (ej. MB) permanecen acopiados (Fig.2) o son llevados a vertedero.

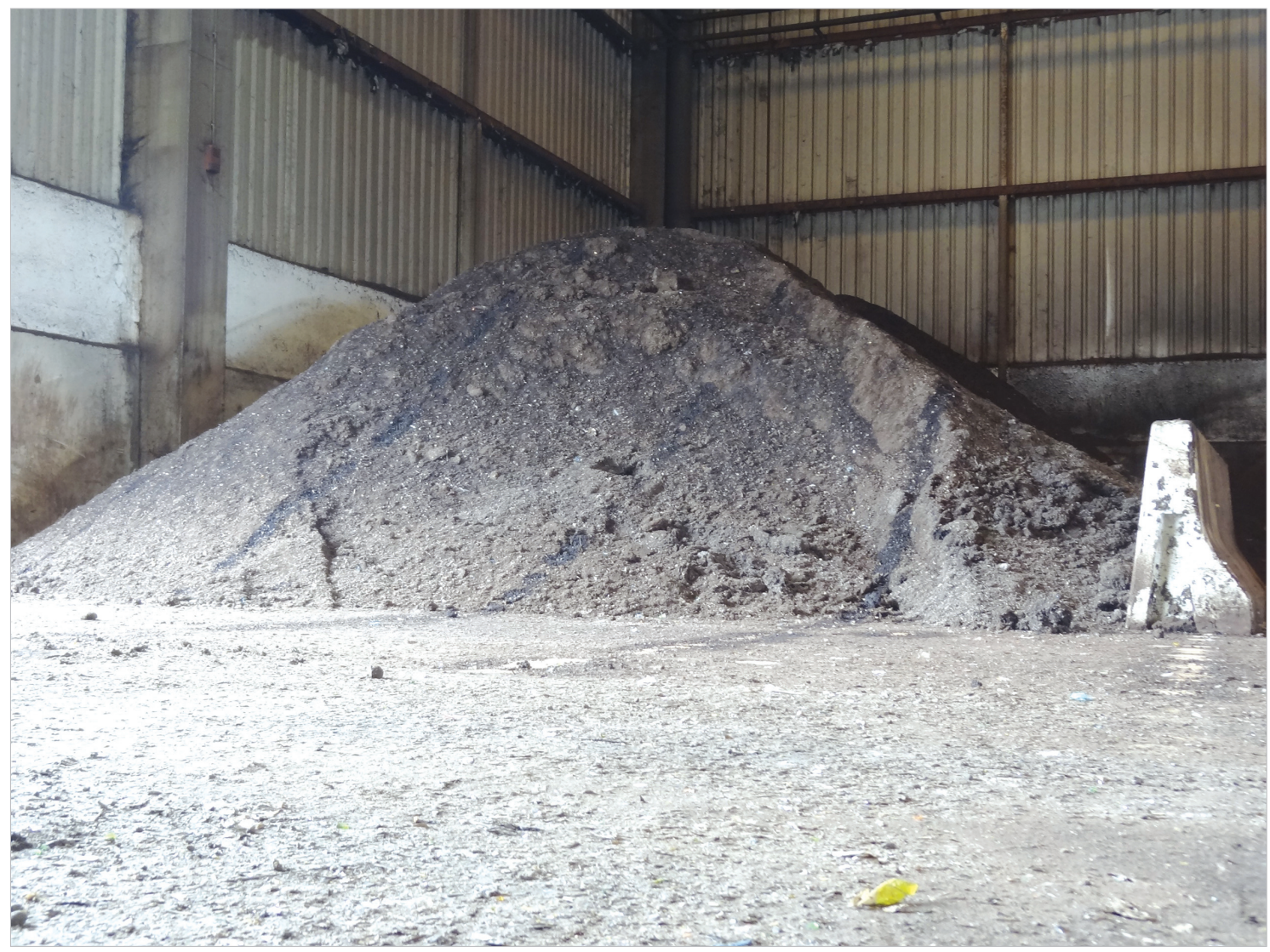

Figura 2. Acopio de MB en la Planta de Biocompost de Álava.

\subsection{Antecedentes}

En 2013 el Ayuntamiento de Vitoria-Gasteiz inició un proyecto experimental de tecnosuelos mediante la combinación de subproductos de plantas municipales, entre ellos el MB, con el fin de generar un suelo artificial que pudiera restaurar espacios degradados. En este proyecto, denominado Proyecto de Tecnosuelos Gardelegi (Herrán A. et al., 2016), se observó que la calidad del suelo mejoraba significativamente en las zonas donde se habían combinado la adición extra de MB y un cultivo energético (Colza). En base a estos resultados, se planteó realizar un ensayo práctico de restauración de suelos degradados siguiendo el método aplicado en el proyecto Tecnosuelos Gardelegi.

\subsection{Objetivo del proyecto}

El objetivo general es testar la mejora de la calidad de un suelo degradado mediante el uso de MB y la rotación de cultivos energéticos, que favorezca su regene- 
ración natural posibilitando la implantación de una infraestructura verde. Se pretende asimismo la restauración del paisaje del emplazamiento, cuya degradación es actualmente muy visible desde la Autovía del Norte A-1 por donde circulan más de 35.000 vehículos al día (PICA, 2009).

Dado el elevado número de parcelas vacantes en el municipio, el modelo a testar podría ser aplicable en otras zonas del municipio o en otras ciudades, especialmente en zonas vacantes próximas a vías de comunicación que por su situación periférica son más apropiadas para soluciones de bajo coste como la aquí propuesta.

\section{4. Ámbito de actuación}

Entre las áreas degradadas del municipio de Vitoria-Gasteiz se escogió una parcela situada al oeste del polígono industrial de Júndiz (Fig.3), propiedad del Ayuntamiento de Vitoria-Gasteiz. Con una superficie de 7 ha, se trata de un ámbito catalogado como Zona Verde en el Plan General de Ordenación Urbana. Sin embargo, su localización periférica y las actividades incontroladas desarrolladas en la zona (vertidos, acopios...) provocaron su degradación.

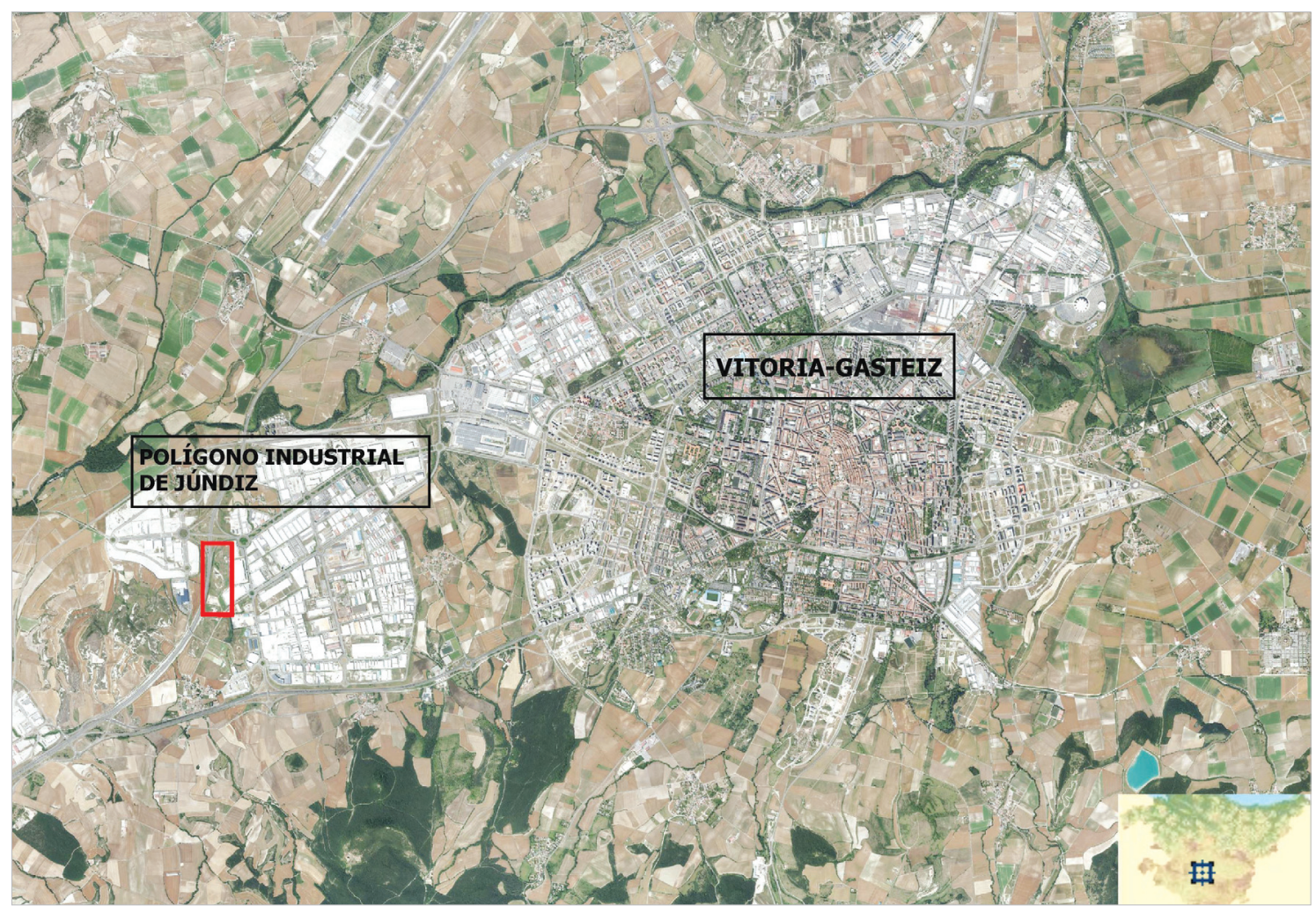

Figura 3. Localización de la parcela degradada de 7 ha (en rojo) situada al oeste del polígono industrial de Júndiz.

Para testar la viabilidad de este modelo de restauración, se ejecutó un primer ensayo piloto sobre 1 ha del terreno (Fig.4). Si los resultados son favorables, se preten- 
de extender el método de restauración al resto de la parcela y a otras de carácter similar.

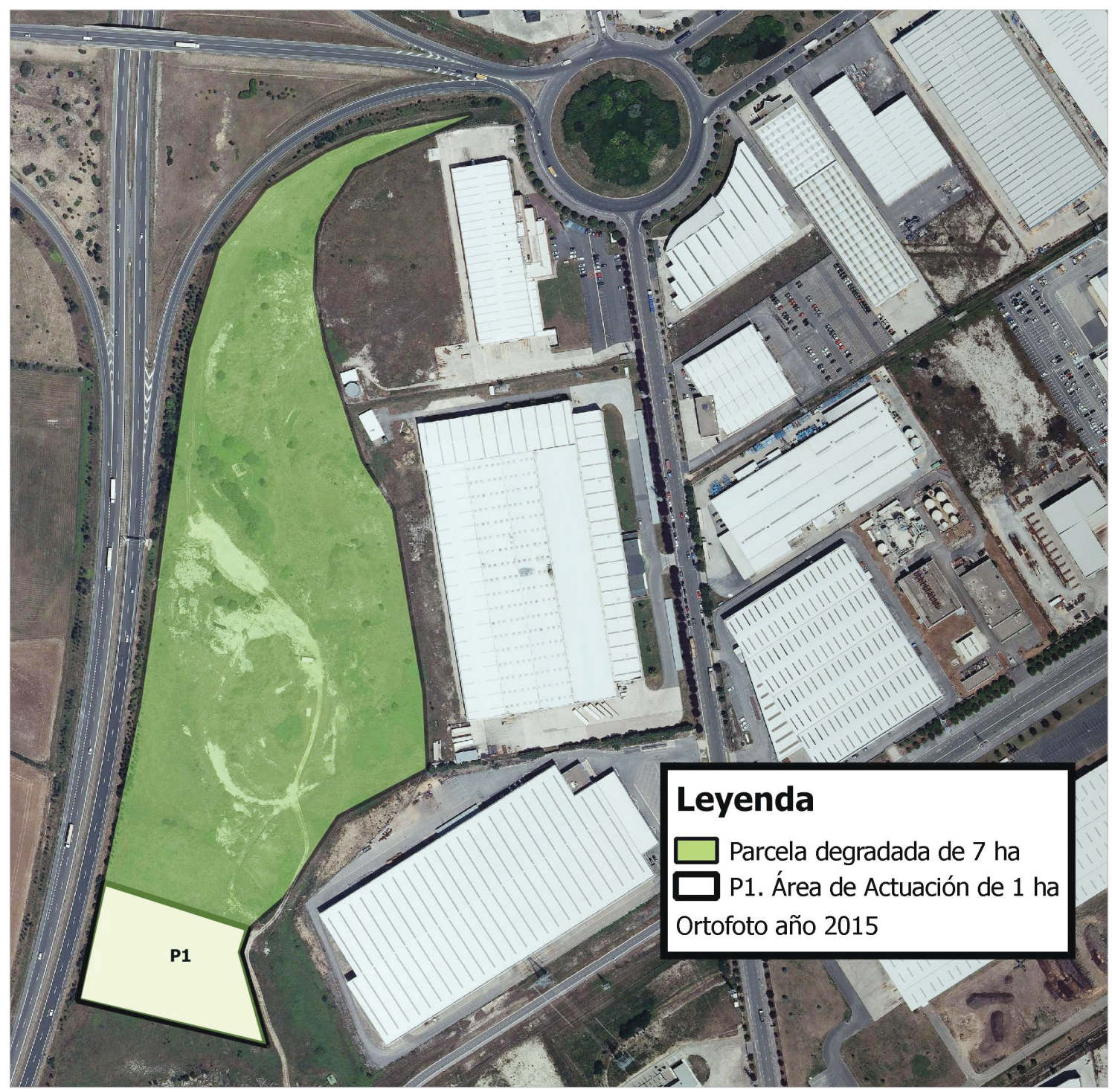

Figura 4. Área de Actuación de 1 ha (P1)

\subsection{Diseño del proyecto}

Para comprobar el efecto que el MB ejerce sobre el suelo y la vegetación se planteó un diseño donde se delimitaron 9 subparcelas (SP) dentro de la parcela de 1 ha (Fig.5). Sobre ellas se aplicaron por triplicado 3 tratamientos:

- Tratamiento 1: parcelas control sin enmienda orgánica (SP1, SP4 y SP7)

- Tratamiento2: dosis de MB de $50 \mathrm{tn} \cdot \mathrm{ha}^{-1}$ (SP2, SP5 y SP8)

— Tratamiento3: dosis de MB de $100 \mathrm{tn} \cdot \mathrm{ha}^{-1}$ (SP3, SP6 y SP9) 


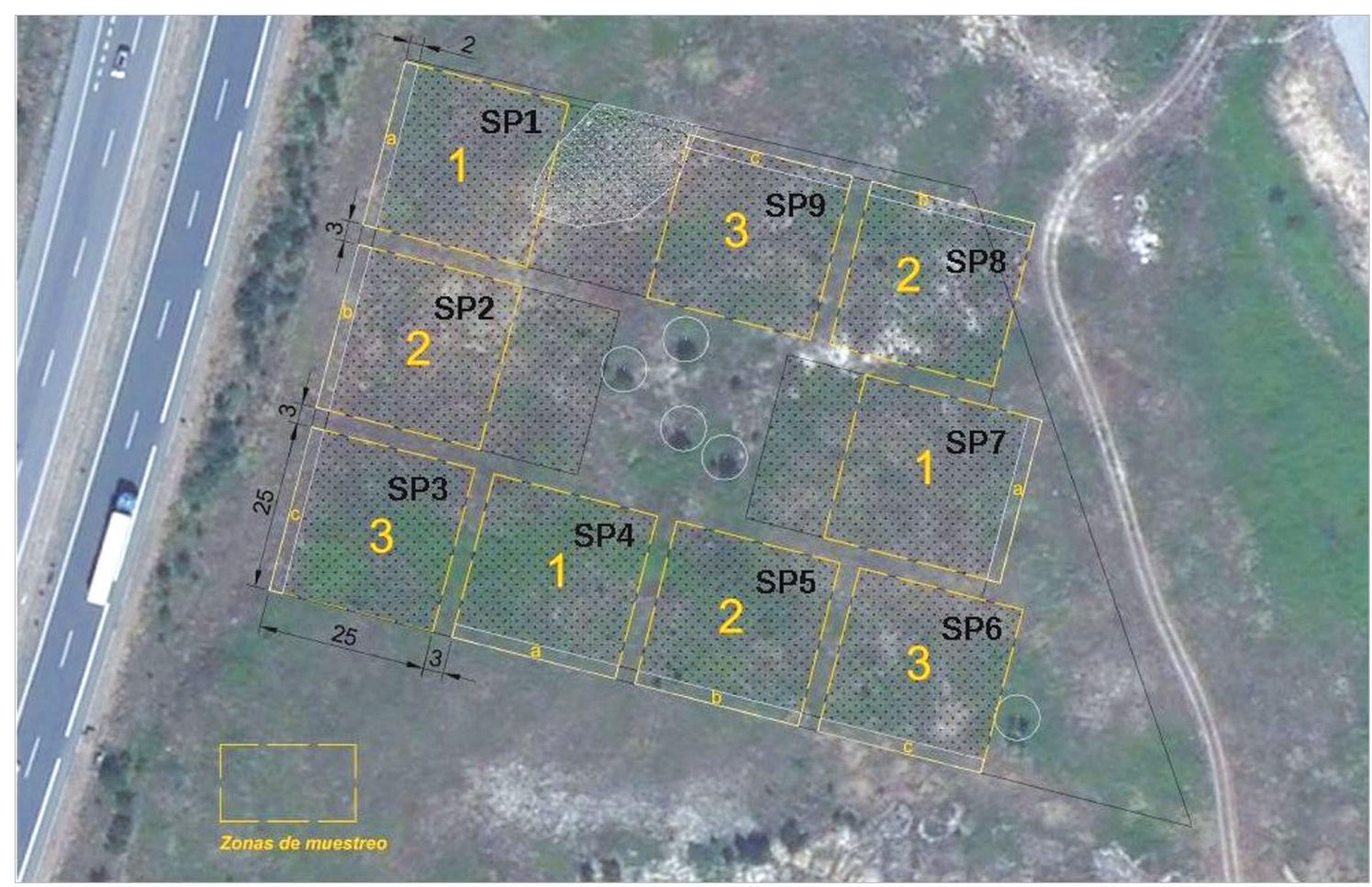

Figura 5. Diseño de la aplicación de los diferentes tratamientos en las subparcelas.

Sobre estas subparcelas se plantearon una serie de controles a fin de comparar con datos objetivos el estado previo y posterior a la actuación, lo que se describe detalladamente en el apartado 3.2.Seguimiento e investigación.

\section{Materiales y métodos}

\subsection{Actuaciones realizadas}

\subsubsection{Acondicionamiento del terreno}

Previamente a la aplicación del MB se acondicionó el terreno (en marzo de 2015). Tras una limpieza general, se desbrozó vegetación espontánea, respetando unos ejemplares de arbolado (chopo) presentes en la parcela. Seguidamente se laboreó el terreno, dejando la parcela lista para las siguientes actuaciones (Fig.6).

Posteriormente se procedió al replanteo, delimitando con cuerdas y estacas las 9 subparcelas junto con pasillos de $3 \mathrm{~m}$ de ancho para facilitar el acceso de maquinaria (Fig.5).

\subsubsection{Analitica del material}

El MB procede de la planta de tratamiento de RSU's "Biocompost de Álava", situada en las proximidades de la parcela. Su empleo requiere la autorización previa del Gobierno Vasco, al tratarse de un producto procedente de residuos y carecer de una 


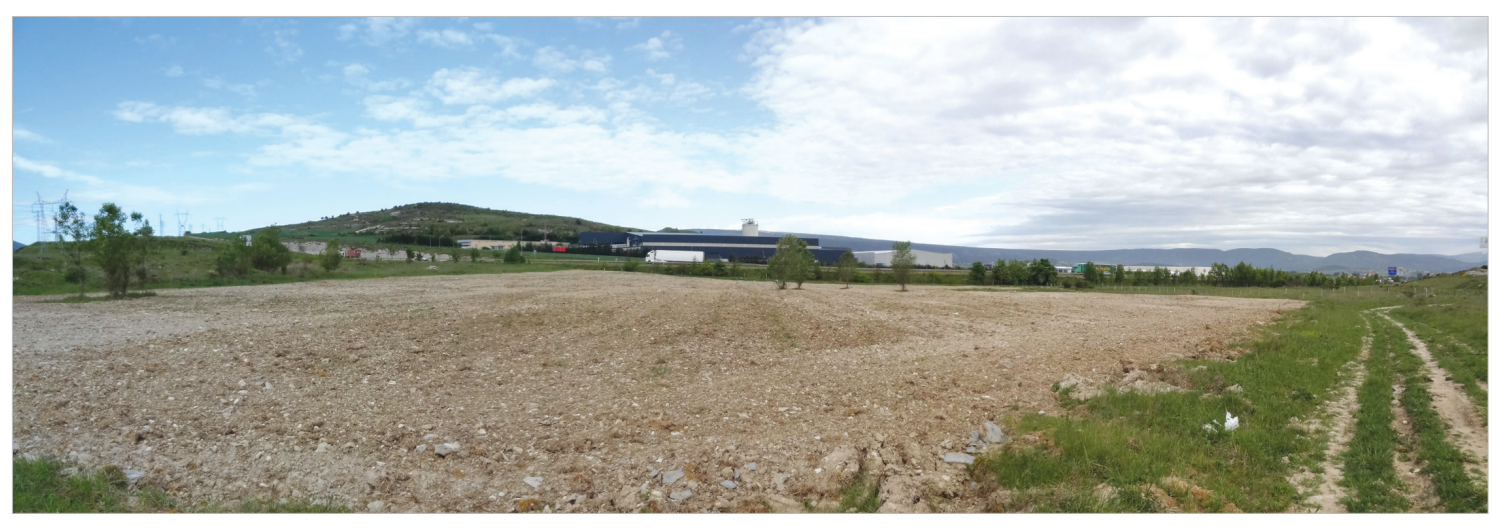

Figura 6. Estado de la parcela tras el acondicionamiento del terreno. Foto: 03/2015

normativa específica para su utilización. Para ello, se caracterizó previamente el MB viendo si se ajustaba a los condicionantes del Gobierno Vasco, establecidos en el documento borrador de junio de 2013 del Ministerio de Agricultura, Alimentación y Medio Ambiente "Decálogo para la utilización de MB fuera de especificación mediante la operación R10".

Para la caracterización, se tomaron varias submuestras del acopio en planta, obteniendo posteriormente una muestra global mediante cuarteo. Nuevamente mediante cuarteo, se obtuvieron tres muestras finales de cantidad similar que fueron analizadas de acuerdo con los parámetros establecidos por el Real Decreto 506/2013, de 28 de junio, sobre productos fertilizantes.

Tras estas analíticas se comprobó que el material a añadir cumplía los requisitos de calidad indicados en la autorización del Gobierno Vasco, pudiendo proceder a su uso.

\subsubsection{Enmienda orgánica}

La adición de MB se llevó a cabo en junio, empleando un camión basculante que cargó en planta la cantidad de MB aproximada, teniendo en cuenta la densidad del material y las dimensiones del remolque. El camión se pesó en báscula ajustando la carga hasta aproximarse a la dosis correspondiente. Una vez descargado el material sobre la subparcela correspondiente (Fig.7) se procedió a la homogeneización de la mezcla (MB + suelo) mediante rotavateado.

\subsubsection{Siembra}

La rotación de cultivos energéticos propuestos comenzó por la siembra de colza (Brassica napus). Este cultivo además de fertilizar el suelo, puede utilizarse posteriormente como biodiesel (aceite de colza) y como alimento para ganado (torta de colza). Al tratarse de parcelas degradadas cabe la posibilidad de que alguna fuente de contaminación no detectada afectase al cultivo, por ello, se decidió incluir un análisis de contaminación de la colza tras su cosecha para determinar su viabilidad como producto alimenticio o energético.

En septiembre se procedió a la siembra de la colza (Fig.8). Se realizó de forma 


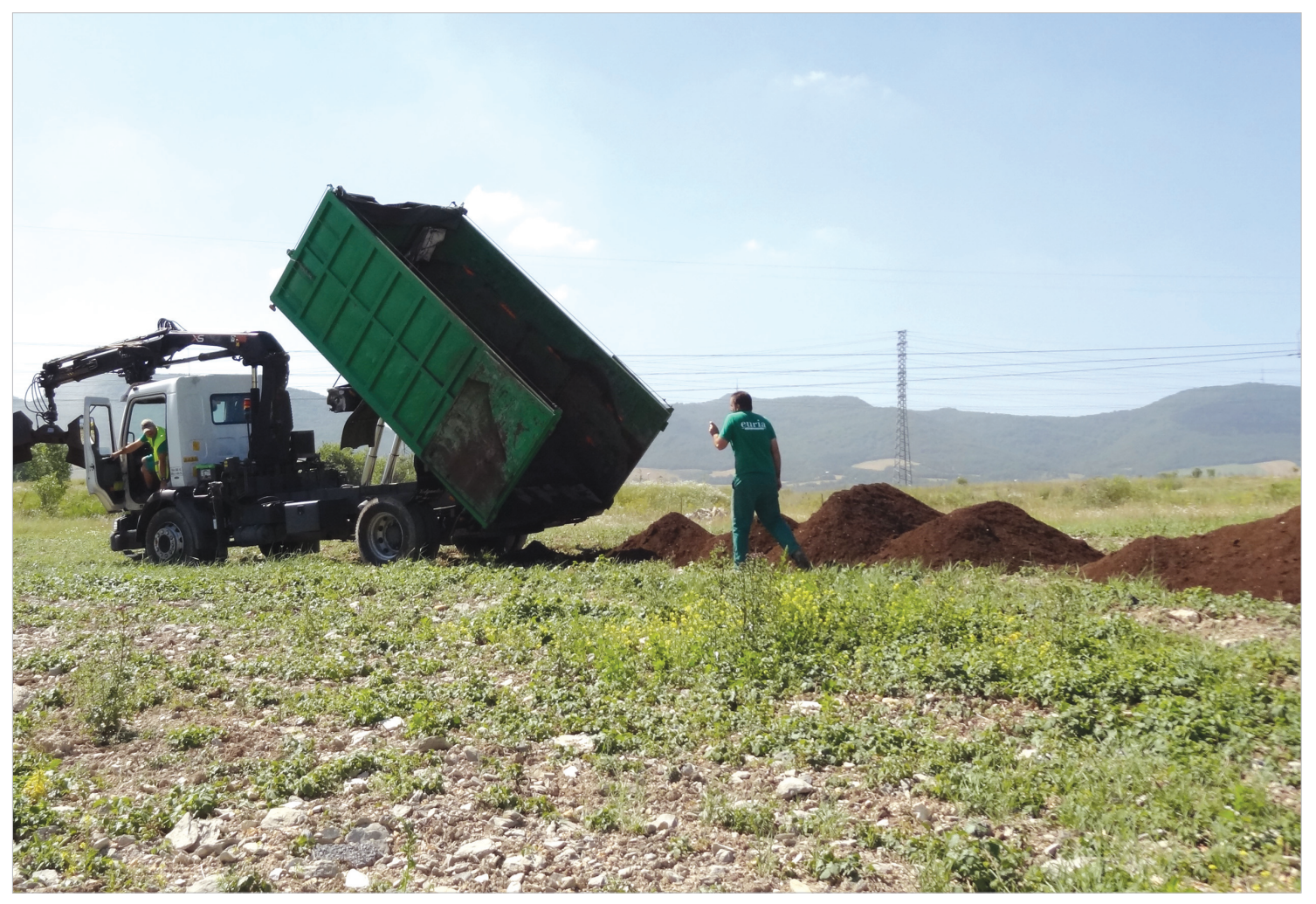

Figura 7. Aplicación del MB. Foto: 24/06/2015

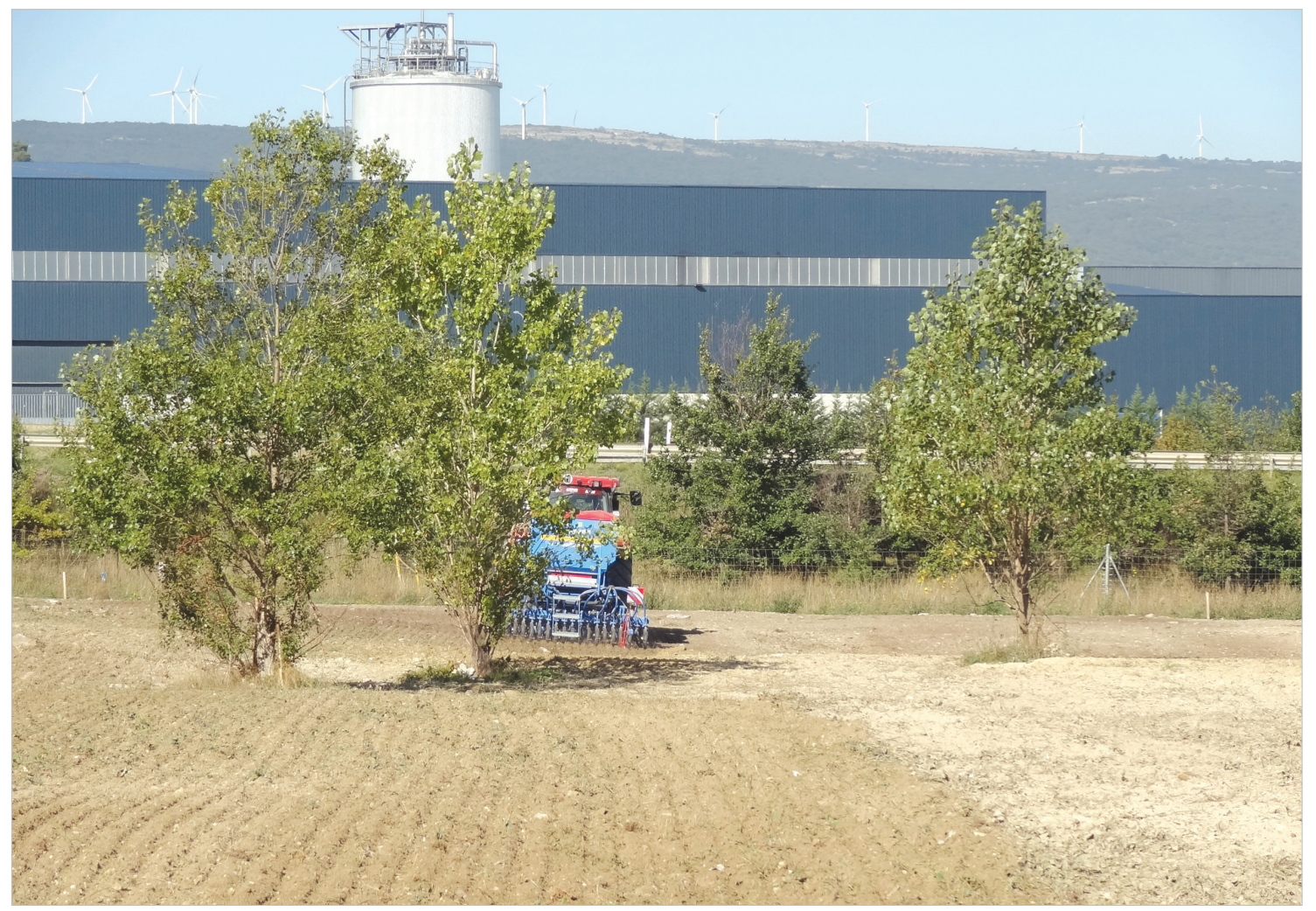

Figura 8. Siembra de la Colza. Foto: 21/09/2015 
mecanizada con una sembradora tipo Lemken. La dosis aproximada fue de 5.680 $\mathrm{kg} \cdot \mathrm{ha}^{-1}$ de colza variedad "Expower", a una profundidad de unos $3 \mathrm{~mm}$ y con una distancia entre líneas de $30 \mathrm{~cm}$.

\subsection{Seguimiento e investigación}

El proyecto incluyó un seguimiento analítico para determinar la efectividad del método de restauración. Se pretende evaluar tanto la evolución de la calidad del suelo como de la vegetación y comprobar si los tratamientos han tenido un impacto positivo en la recuperación de la parcela y en la mejora de la calidad del paisaje.

\subsubsection{Seguimiento del suelo}

Se propuso efectuar tres analíticas en diferentes momentos, a fin de determinar por comparación el efecto que cada fase del proyecto tiene sobre el suelo. La primera se realizó en octubre de 2014, previamente a cualquier actuación, con el objeto de caracterizar el suelo receptor y obtener unos datos de referencia iniciales. La segunda, en septiembre de 2015, se realizó unos meses después de la adición del MB pero antes de la siembra del cultivo, con el fin determinar el efecto inicial del MB sobre el suelo. La última, se realizará tras la cosecha del cultivo (previsto para el mes de julio de 2016) para determinar el efecto conjunto que ejercen sobre el sustrato la combinación de MB y el cultivo de colza.

El método para la toma de muestras consiste en seleccionar un punto de cada subparcela del cual se extrae una muestra de suelo mediante un barreno sacamuestras. La elección de este punto se realiza siguiendo el mismo patrón en todas las subparcelas (Fig.9).

Para caracterizar el suelo receptor se realizó un análisis físico-químico inicial de las muestras recogidas previamente al comienzo con las actuaciones. Por otra parte, para determinar la salud del suelo y su evolución a lo largo del proyecto, se realizó un análisis de las propiedades microbiológicas y un bioensayo de toxicidad a las muestras recogidas una vez comenzadas las actuaciones del presente proyecto. Estas últimas analíticas se repetirán en las muestras tomadas tras la cosecha del cultivo:

- El análisis físico-químico se realizó con objeto de determinar si el suelo cumplía con las características de un suelo no contaminado, definidas por los niveles del VIE-B “otros usos" establecidos por la Ley 4/2015, de 25 de junio, para la prevención y corrección de la contaminación del suelo.

- El análisis microbiológico, realizado por Neiker-Tecnalia y la EHU/UPV, se efectuó para poder determinar la existencia de microorganismos en el suelo. Éstos son un bioindicador de la calidad del suelo; a mayor cantidad y diversidad de microorganismos, mejor calidad de suelo. Para ello se compararon muestras de los 3 tratamientos junto con un suelo adyacente como control adicional, al objeto de establecer comparaciones. Las propiedades microbianas medidas fueron la actividad $\beta$-glucosidasa, respiración basal, RISrespiración inducida por sustrato, CMB-carbono de la biomasa microbiana, NPM-nitrógeno potencialmente mineralizable, AWCD-desarrollo de color 


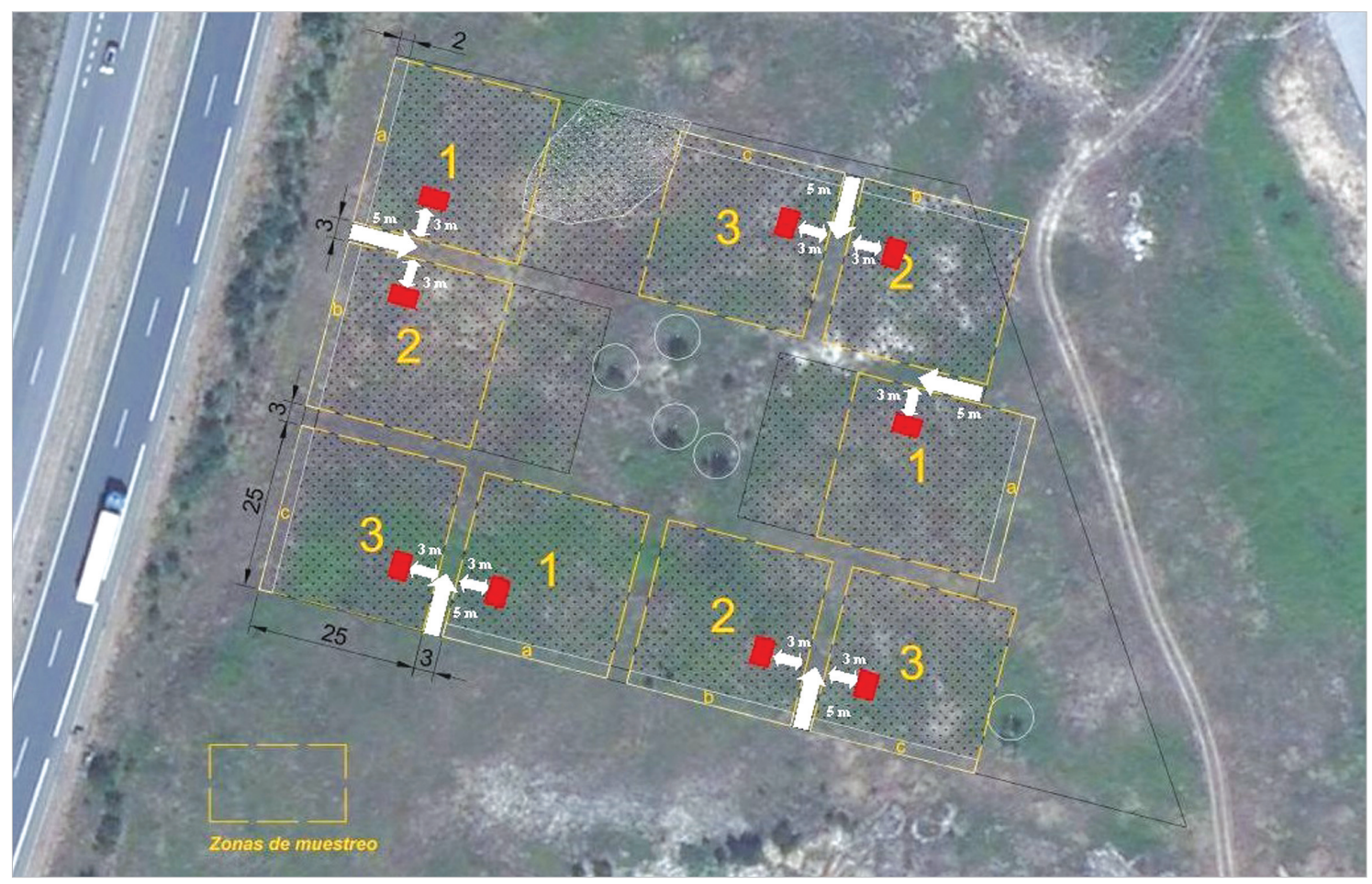

Figura 9. Patrón seguido para la toma de muestras de suelo y vegetación (en rojo los puntos de muestreo).

medio en las Biolog Ecoplates, NUS-número de sustratos utilizados en las Biolog Ecoplates y el índice de Shannon.

- El bioensayo de toxicidad, realizado por la UPV/EHU, es una herramienta para evaluar la toxicidad de una muestra basándose en sus efectos sobre organismos vivos cuidadosamente escogidos (en este caso Cucumis sativus) y bajo condiciones específicas de ensayo. El bioensayo consistió en exponer la semilla a los suelos de estudio durante $48 \mathrm{~h}$ en una cámara de germinación y posteriormente determinar la tasa de elongación radical y el contenido en compuestos antioxidantes lipofílicos (García-Plazaola y Becerril, 1999 y 2001).

\subsubsection{Seguimiento del cultivo}

Se plantea realizar dos evaluaciones del estado del cultivo durante el proyecto y, al igual que con el suelo, repetir los mismos análisis para comparar los resultados y determinar el efecto que el MB y el suelo tienen sobre el cultivo. La primera evaluación se realizó en noviembre de 2015 y la segunda, se realizará en el momento de la cosecha para determinar la salud de la colza y, si los hubiese, los efectos que el suelo degradado y el MB hayan podido tener sobre el cultivo.

E1 método para la toma de muestras consiste en recoger las plantas enteras de un área de $1 \mathrm{~m}^{2}$, que se selecciona siguiendo siempre el mismo patrón (Fig.9). Estas plantas se separan por parte aérea $(\mathrm{PA})$ y raíz $(\mathrm{R})$ y se guardan en bolsas de plástico junto con un paño húmedo para evitar su desecación. 
Una vez en el laboratorio, la UPV/EHU realiza diferentes análisis:

- Los análisis biométricos y de producción de biomasa están directamente relacionados ya que determinan el crecimiento del cultivo. Los análisis biométricos consisten en determinar las medidas en $\mathrm{m}^{2}$ de la PA y la $\mathrm{R}$ y la producción de biomasa se determina mediante el pesado, secado y posterior pesado de las plantas. Este último ensayo sirve para determinar el contenido en materia seca (PS), el contenido hídrico PF-PS y la relación peso fresco/seco (PF/PS) de la planta (Artetxe U. et al., 2002).

- Para el análisis de los parámetros fisiológicos se analiza la eficiencia fotoquímica de la fotosíntesis $(\mathrm{Fv} / \mathrm{Fm})$ y el estado hídrico de las plantas con el fin de determinar la contribución y estado de los procesos fotosintéticos. Además, también se analiza el contenido en pigmentos (clorofilas, carotenoides y pigmentos de VAZ) y antioxidantes (isómeros de tocoferol) del cultivo para determinar si la planta se encuentra en estado de estrés (García-Plazaola y Becerril, 1999 y 2001).

Además de los análisis, se ha realizado un seguimiento del estado fenológico de la colza en sus diferentes estadios para evaluar su desarrollo. Esto consiste en monitorizar el crecimiento del cultivo siguiendo las etapas normales (estadios fenológicos) que se determinan en la escala $\mathrm{BBCH}$ de la colza. Al ser las etapas tempranas del cultivo las más vulnerables a los agentes externos, se realizó un seguimiento más exhaustivo de las mismas.

\subsubsection{Seguimiento del paisaje}

Se ha incluido un seguimiento fotográfico para analizar desde varios puntos de control la la calidad paisajística del emplazamiento. Las series de fotos secuenciads en el tiempo muestran la evolución del cultivo sobre la parcela y su relación con el entorno.

\section{Resultados}

Los datos presentados a continuación muestran la evolución hasta abril de 2016.

\subsection{Suelo}

\subsubsection{Análisis físico-químicos del suelo}

En el análisis fisco-químico se observó que todos los parámetros se encontraban bajo los niveles establecidos en el VIE-B "otros usos", un $\mathrm{pH}$ de 8,6 , un contenido en materia orgánica $(\mathrm{MO})$ de $1 \%$ y una relación $\mathrm{C} / \mathrm{N}$ de 6,7 .

\subsubsection{Análisis microbiológicos del suelo}

Al objeto de tener una primera estimación del efecto de los tratamientos sobre el suelo, se estudiaron las medias aritméticas de las propiedades microbianas con poten- 
cial bioindicador de la salud del suelo. El efecto de los tratamientos con MB sobre el conjunto de los parámetros microbianos se determinó gráficamente mediante dos diagramas ameba; en el primero se utilizó como suelo de referencia el suelo adyacente (Fig.10) y en el segundo el suelo con tratamiento 1 (Fig.11).

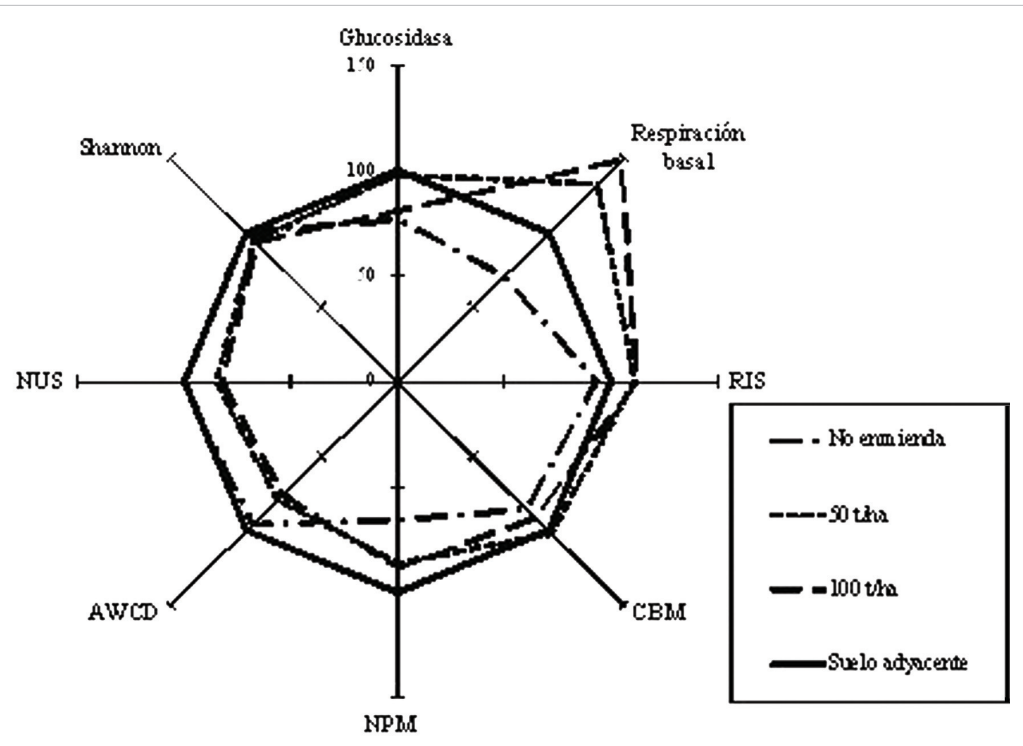

Figura 10. Diagrama ameba del efecto de los diferentes tratamientos sobre los parámetros microbianos del suelo. Suelo de referencia: Suelo adyacente.

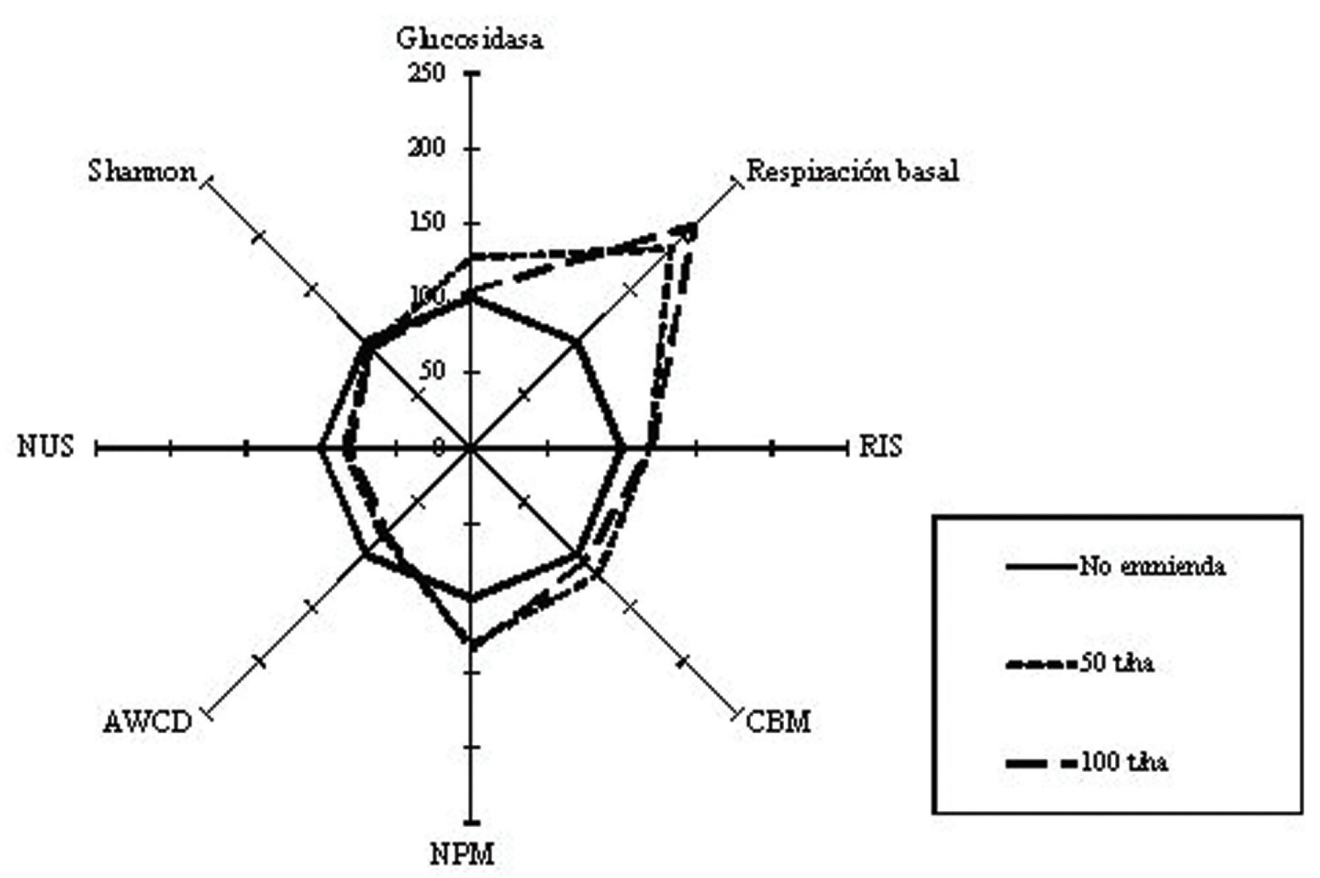

Figura 11. Diagrama ameba del efecto de los diferentes tratamientos sobre los parámetros microbianos del suelo. Suelo de referencia: Suelo Control. 
Tras el ensayo se observó que de los parámetros microbianos analizados, únicamente la respiración basal (indicador de la actividad biológica total del suelo) mostró valores significativamente más altos en los suelos tratados con MB.

\subsubsection{Bioensayo de toxicidad del suelo}

Los resultados de fitotoxicidad (Tab.1) indicaron que la aplicación de la enmienda a cualquiera de las dosis no causa reducción en la elongación radical de $C$. sati$v u s$, ni altera el nivel de metabolitos antioxidantes analizados.

Tabla 1. Bioensayo de toxicidad de Cucumis sativus.

\begin{tabular}{cccc}
\hline \multirow{2}{*}{ Bioensayo } & \multicolumn{3}{c}{ Tratamiento } \\
\cline { 2 - 4 } & $\mathrm{T} 1\left(0 \mathrm{tn} \cdot \mathrm{ha}^{-1}\right)$ & $\mathrm{T} 2\left(50 \mathrm{tn} \cdot \mathrm{ha}^{-1}\right)$ & $\mathrm{T} 3\left(100 \mathrm{tn} \cdot \mathrm{ha}^{-1}\right)$ \\
\hline Elongación radical $(\mathrm{mm})$ & $32.07 \pm 1.58$ & $30.23 \pm 2.71$ & $31.64 \pm 2.67$ \\
$\alpha$-tocoferol $\left(\mathrm{nmol} \cdot \mathrm{g}^{-1} \mathrm{PF}\right)$ & $0.94 \pm 0.15$ & $0.93 \pm 0.17$ & $0.72 \pm 0.14$ \\
\hline
\end{tabular}

\subsection{Cultivo}

\subsubsection{Seguimiento fenológico del cultivo}

Se observaron diferencias significativas en el crecimiento y desarrollo de la vegetación con los diferentes tratamientos (Fig. 12). Los suelos con tratamiento 1 presentaron un menor crecimiento y desarrollo que los suelos enmendados. Por ejemplo, a principios de diciembre la colza de los suelos no enmendados estaba en un estado fenológico 16 mientras que la desarrollada en suelos enmendados se encontraba en estado fenológico 17.

En la visita realizada a la parcela en abril de 2016 se observó que todas las plantas se encontraban en un estado fenológico 61- 62 (Fig.13), mostrando variación de tamaño y siendo las plantas con tratamiento 1 las menos desarrolladas.

\subsubsection{Análisis biométricos y de producción de biomasa del cultivo}

El análisis biométrico de la colza mostró un mayor crecimiento de las plantas desarrolladas en las subparcelas enmendadas (Tab.2), puesto que el tamaño de sus órganos aéreos y subterráneos fue superior a los de las subparcelas sin $\mathrm{MB}$ (tratamiento 1).

Además, según las analíticas, las plantas con tratamiento 2 mostraron un mayor desarrollo incluso que las desarrolladas con tratamiento 3, lo que indica que las concentraciones de 50 tn’ha-1 son más apropiadas para el desarrollo de la vegetación.

\subsubsection{Análisis fisiológico del cultivo}

Se observó que la enmienda tiene un efecto muy positivo sobre la ganancia de MO y sobre el tamaño final de las plantas (Tab.3). Por un lado, los valores de la eficiencia fotoquímica se encontraban dentro del rango normal en todos los casos y, por otro lado, las plantas enmendadas mostraron un mejor estado hídrico de los tejidos fotosintéticos en comparación con las plantas control. 


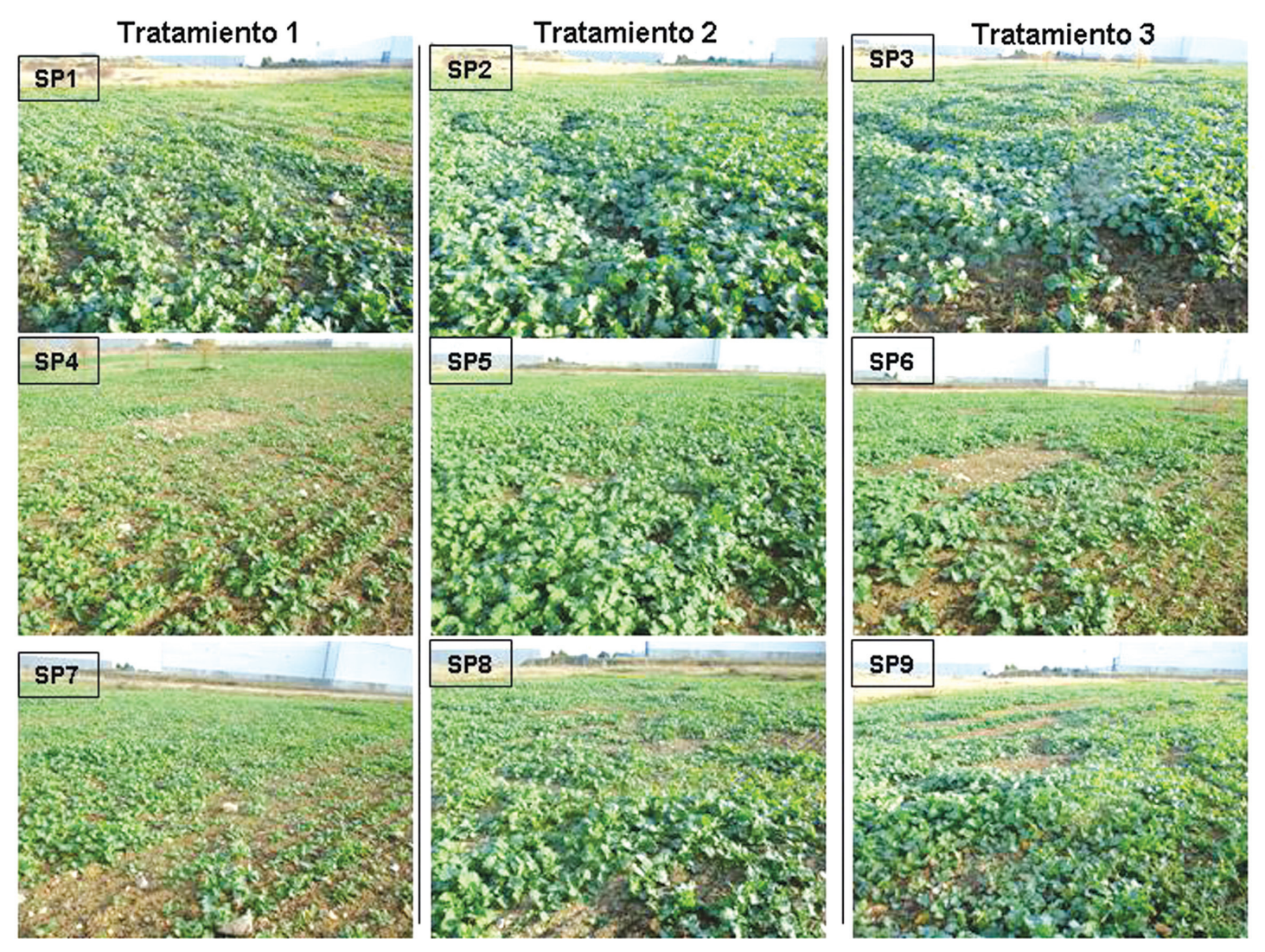

Figura 12. Evolución de la Colza entre las diferentes subparcelas. Fotos: 03/12/2015

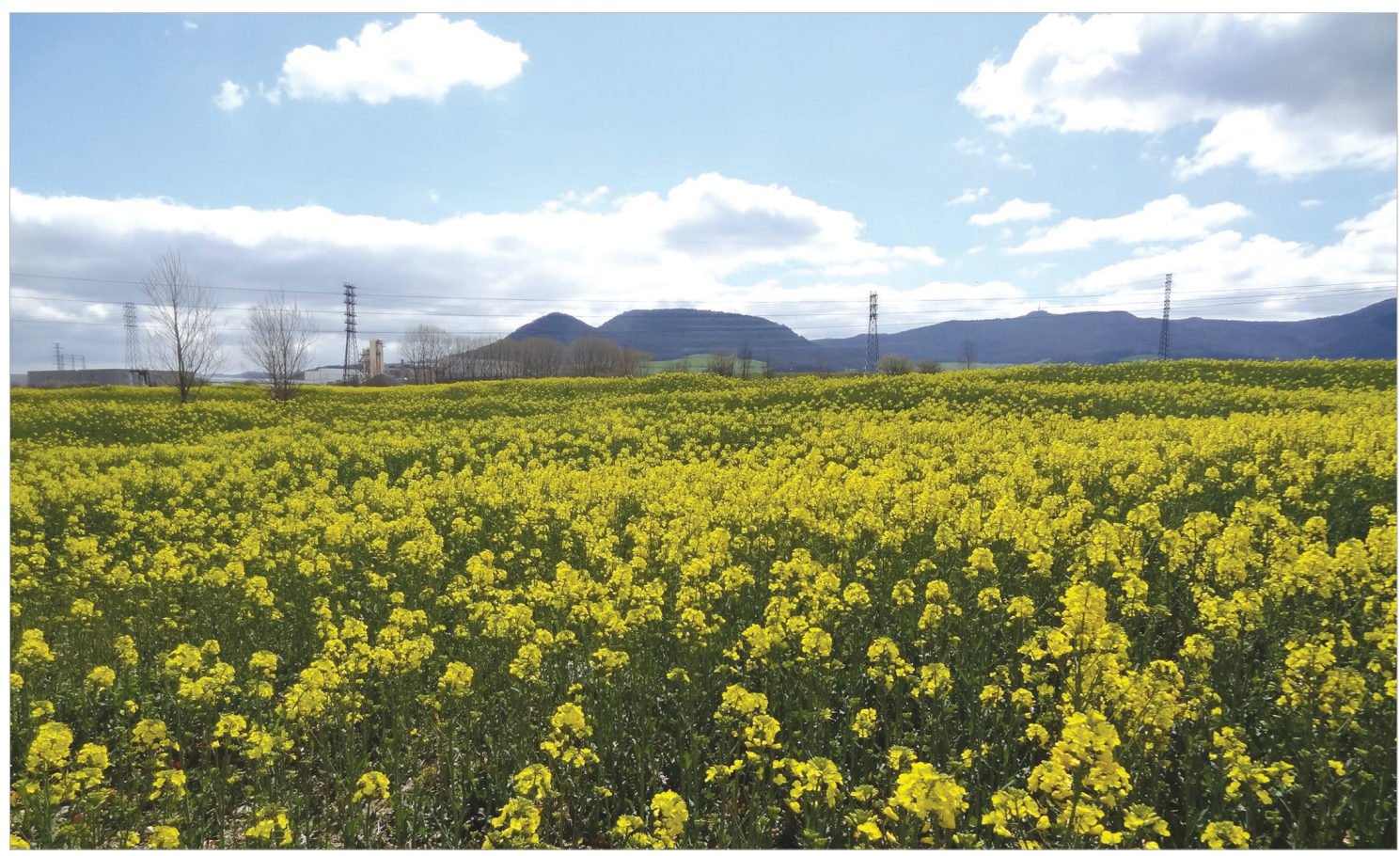

Figura 13. Vista general de la Colza en estadio BBCH 61-62. Foto: 06/04/2016 
Tabla 2. Parámetros biométricos y de producción de biomasa del cultivo en estadio BBCH 16-17.

\begin{tabular}{cccc}
\hline \multirow{2}{*}{ Parámetros Biométricos } & \multicolumn{3}{c}{ Tratamiento } \\
\cline { 2 - 4 } & $\mathrm{T} 1\left(0 \mathrm{tn} \cdot \mathrm{ha}^{-1}\right)$ & $\mathrm{T} 2\left(50 \mathrm{tn} \cdot \mathrm{ha}^{-1}\right)$ & $\mathrm{T} 3\left(100 \mathrm{tn} \cdot \mathrm{ha}^{-1}\right)$ \\
\hline $\mathrm{N}^{\mathrm{o}}$ hojas & $6.00 \pm 0.400$ & $7.56 \pm 0.25$ & $7.06 \pm 0.29$ \\
Área foliar $\left(\mathrm{cm}^{2}\right)$ & $122 \pm 29.9$ & $405 \pm 39.9$ & $318 \pm 45.2$ \\
Área radical $\left(\mathrm{cm}^{2}\right)$ & $7.82 \pm 1.84$ & $31.89 \pm 3.98$ & $22.71 \pm 3.40$ \\
Peso Fresco Total $(\mathrm{g})$ & $7.48 \pm 2.24$ & $27.52 \pm 3.12$ & $20.46 \pm 3.30$ \\
Peso Seco Total $(\mathrm{g})$ & $0.90 \pm 0.23$ & $2.91 \pm 0.31$ & $1.99 \pm 0.31$ \\
Peso Fresco Parte Aérea (g) & $6.67 \pm 2.05$ & $25.65 \pm 2.96$ & $19.39 \pm 3.15$ \\
Peso Seco Parte Aérea (g) & $0.79 \pm 0.21$ & $2.67 \pm 0.29$ & $1.85 \pm 0.29$ \\
Peso Fresco Raíz (g) & $0.80 \pm 0.20$ & $1.87 \pm 0.20$ & $1.08 \pm 0.16$ \\
Peso Seco Raíz (g) & $0.11 \pm 0.02$ & $0.24 \pm 0.03$ & $0.14 \pm 0.02$ \\
\hline
\end{tabular}

Tabla 3. Determinación del estado físiológico del cultivo en estadio BBCH 16-17.

\begin{tabular}{cccc}
\hline \multirow{2}{*}{ Parámetros Fisiológicos } & \multicolumn{3}{c}{ Tratamiento } \\
\cline { 2 - 4 } & $\mathrm{T} 1\left(0 \mathrm{tn} \cdot \mathrm{ha}^{-1}\right)$ & $\mathrm{T} 2\left(50 \mathrm{tn} \cdot \mathrm{ha}^{-1}\right)$ & $\mathrm{T} 3\left(100 \mathrm{tn} \cdot \mathrm{ha}^{-1}\right)$ \\
\hline Fv/Fm & $0.765 \pm 0.007$ & $0.777 \pm 0.005$ & $0.788 \pm 0.007$ \\
PF/PS Parte Aérea & $7.803 \pm 0.389$ & $9.583 \pm 0.312$ & $10.525 \pm 0.396$ \\
PF/PS Raíz & $7.229 \pm 0.316$ & $7.995 \pm 0.340$ & $8.219 \pm 0.374$ \\
\hline
\end{tabular}

Tabla 4. Contenido en pigmentos y antioxidantes del cultivo en estadio BBCH 16-17.

\begin{tabular}{cccc}
\hline \multirow{2}{*}{ Pigmentos $\left(\mathrm{nmol} \cdot \mathrm{g}^{-1} \mathrm{PF}\right)$} & \multicolumn{3}{c}{ Tratamiento } \\
\cline { 2 - 4 } & $\mathrm{T} 1\left(0 \mathrm{tn} \cdot \mathrm{ha}^{-1}\right)$ & $\mathrm{T} 2\left(50 \mathrm{tn} \cdot \mathrm{ha}^{-1}\right)$ & $\mathrm{T} 3\left(100 \mathrm{tn} \cdot \mathrm{ha}^{-1}\right)$ \\
\hline Clorofila b & $54.2 \pm 3.60$ & $63.6 \pm 2.28$ & $65.5 \pm 2.21$ \\
Clorofila a & $193 \pm 13.0$ & $224 \pm 9.0$ & $227 \pm 8.6$ \\
Clorofila total & $247 \pm 16.6$ & $288 \pm 11.2$ & $293 \pm 10.6$ \\
\hline Violaxantina & $21.7 \pm 1.71$ & $21.7 \pm 1.27$ & $20.5 \pm 1.36$ \\
Anteraxantina & $0.35 \pm 0.04$ & $0.47 \pm 0.05$ & $0.29 \pm 0.04$ \\
Zeaxantina & $0.46 \pm 0.08$ & $0.72 \pm 0.10$ & $0.37 \pm 0.07$ \\
VAZ total & $22.47 \pm 1.78$ & $22.8 \pm 1.35$ & $21.1 \pm 1 . .43$ \\
\hline Neox & $8.12 \pm 0.47$ & $9.00 \pm 0.36$ & $9.08 \pm 0.31$ \\
Luteina & $33.11 \pm 1.89$ & $33.7 \pm 1.26$ & $34.4 \pm 1.45$ \\
$\beta$-caroteno & $23.46 \pm 1.50$ & $26.1 \pm 1.15$ & $26.1 \pm 1.10$ \\
Carotenoides totales & $87.17 \pm 5.41$ & $91.69 \pm 3.91$ & $90.72 \pm 4.04$ \\
\hline$\delta$ - tocoferol & $0.01 \pm 0.00$ & $\mathrm{n} \cdot \mathrm{d}$ & $\mathrm{n} \cdot \mathrm{d}$ \\
$\beta$ + $\gamma$ tocoferol & $0.18 \pm 0.06$ & $0.09 \pm 0.01$ & $0.05 \pm 0.02$ \\
$\alpha$-tocoferol & $15.9 \pm 4.17$ & $23.7 \pm 6.67$ & $15.2 \pm 6.46$ \\
Tocoferoles totales & $15.88 \pm 4.17$ & $23.70 \pm 6.67$ & $15.17 \pm 6.46$ \\
\hline
\end{tabular}


Los resultados de los parámetros fisiológicos mostraron un contenido de clorofila un $20 \%$ superior a las plantas controles en las plantas con enmienda. Por otro lado, ni los pigmentos implicados en la fotoprotección (VAZ) ni los niveles de antioxidantes se vieron alterados (Tab.4).

\subsection{Paisaje}

Se muestra como ejemplo una serie fotográfica de dos puntos de control del paisaje. Partiendo de un aspecto inicial de contaminación visual por vertidos incontrolados (Fig.14) se pasa a un paisaje agrícola en producción que muestra los diferentes estados de crecimiento del cultivo (floración, formación de semilla,...) y traslada una imagen de territorio atendido (Fig. 15).

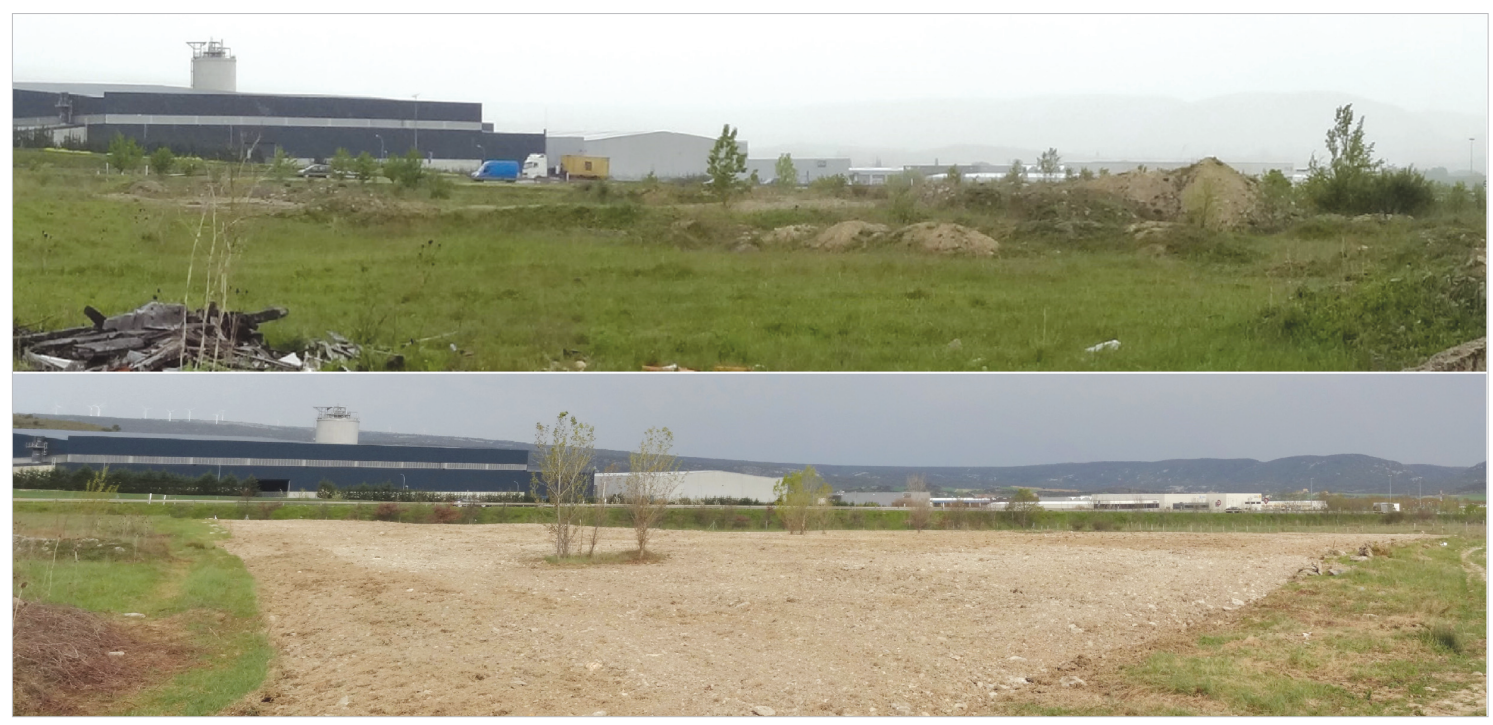

Figura 14. Evolución inicial del paisaje de Júndiz.

\section{Discusión}

El análisis fisco-químico de caracterización del suelo receptor determinó que el suelo no se encontraba contaminado, al estar los parámetros bajo los niveles establecidos en el VIE-B “otros usos”. Sin embargo, se detectó una escasez notable de MO y un valor bajo en la relación carbono/nitrógeno, poniendo de manifiesto la degradación o esterilidad de un suelo antiguamente usado como parcela agrícola.

Por otro lado, los análisis microbiológicos mostraron valores significativamente más elevados de respiración basal en los suelos tratados con $\mathrm{MB}$, lo que indicaba una mayor actividad biológica total en los suelos enmendados. Este efecto estimulador de la actividad respiratoria fue el primer efecto beneficioso observado, a corto plazo, de la adición de la enmienda orgánica. 


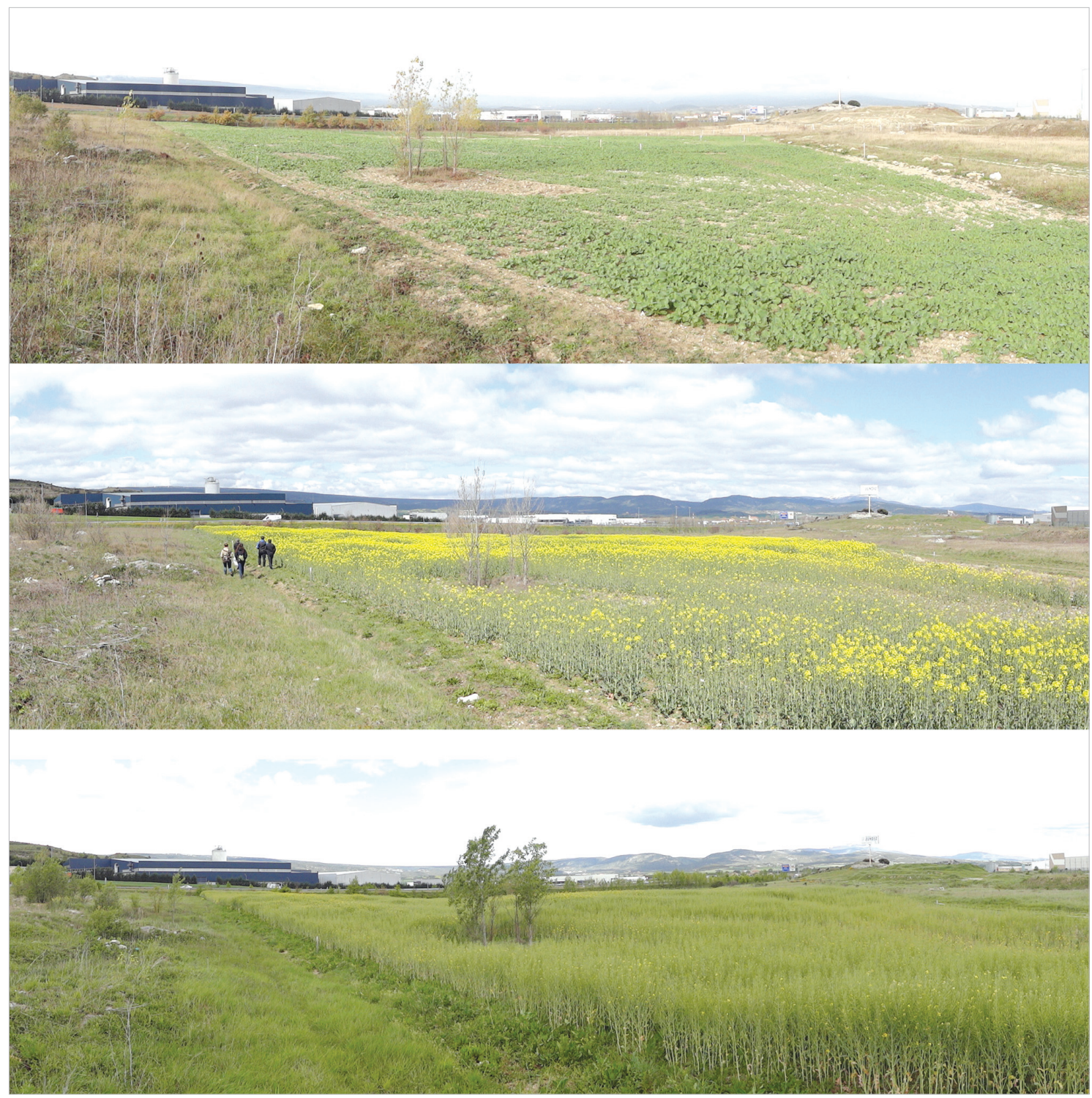

Figura 15. Evolución del paisaje de Júndiz en función del desarrollo del cultivo.

Respecto al bioensayo de toxicidad, no se observaron alteraciones en la elongación radical, lo que reflejaba un desarrollo normal de C. sativus y corroboraba la capacidad del suelo para albergar especies vegetales. Además, no se vio alterado el contenido de antioxidantes en la planta, lo que indicaba una ausencia de fitotoxicidad en la misma, ya que son compuestos que las especies vegetales generan cuando se encuentran en estado de estrés. Es decir, se demostró una ausencia de contaminación en el suelo estudiado y una falta de compuestos dañinos para la salud de la vegetación.

Los resultados biométricos indicaron que la aplicación de la enmienda tiene un efecto muy positivo incrementando el número de hojas y el área foliar total. Este incremento del área fotosintética aumenta la cantidad de carbono total fijado por la 
planta. De hecho, las plantas con enmienda mostraron una mayor biomasa total determinada como materia seca ( 3 veces mayor en $50 \mathrm{tn} \cdot \mathrm{ha}^{-1}$ y 2 veces mayor en 100 tn $\left.\cdot h a^{-1}\right)$. Al analizar la distribución de materia seca entre los órganos de la planta, se observó que es en los órganos de la PA donde la ganancia en materia seca era mayor. En los tratamientos con enmienda, además, se modificó la arquitectura radical, ya que se observó la presencia de un mayor número de raicillas en comparación con el control. Esta mayor superficie de absorción podría contribuir a la mejora del estado nutricional de la planta.

Los resultados fisiológicos no mostraron alteraciones en los valores de $\mathrm{Fv} / \mathrm{Fm}$, lo que indicaba que tanto las plantas enmendadas como las no enmendadas no presentaban alteraciones en los procesos fotosintéticos. Además, el mayor contenido en clorofila de las plantas desarrolladas en las subparcelas con MB justificaba su mayor capacidad fotosintética por unidad de tejido, e indirectamente indicaba un mejor estado nutricional de las mismas. Los valores de VAZ no mostraron alteraciones, lo que significa que ninguna de las plantas de los tratamientos sufría estrés. Estos resultados demuestran que la aplicación de MB no genera efectos negativos en la vegetación.

En relación al paisaje de la parcela, se ha observado una reducción significativa del impacto visual que la parcela generaba y una mejora de su calidad escénica.

\section{Conclusiones}

Con los resultados obtenidos hasta abril de 2016 se puede concluir que la aplicación de $\mathrm{MB}$ a las dosis de $50 \mathrm{tn} \cdot \mathrm{ha}^{-1}$ y $100 \mathrm{tn} \cdot \mathrm{ha}^{-1}$ al suelo no causa fitotoxicidad ni altera la salud del suelo, al contrario, el MB favorece la respiración basal del suelo, lo que se traduce en una mayor actividad biológica total que demuestra una mejora de la calidad del suelo.

Por otro lado, la adición de MB mejora el estado nutricional del suelo, lo que favorece el crecimiento de las raíces de la planta, que contribuye positivamente al estado nutricional del cultivo. Este hecho justifica el aumento de la fotosíntesis en las plantas enmendadas, lo que permite que presenten una mayor biomasa total. Por lo que, la adición de MB no sólo favorece el desarrollo de la vegetación, sino que lo hace sin causar ningún estrés, ni efectos tóxicos sobre el cultivo.

La calidad paisajística también ha mejorado, relacionándose ahora la estética de la parcela con el entorno rural agrícola.

En todo caso, hay que señalar que los resultados completos del proyecto se obtendrán tras repetir los ensayos posteriormente a la cosecha del cultivo (prevista en julio de 2016). Además, sería interesante ampliar la investigación para evaluar la calidad y aptitud de la colza en cuanto a sus posibles usos futuros, bien como como biocombustible o alimento para ganado, con el fin de cerrar el ciclo productivo bajo el prisma de la economía circular y de valorización de residuos. Aplicando la restauración al resto de parcelas degradadas en torno corredor de la A-1, se podrá mejorar los suelos y el paisaje del municipio de Vitoria-Gasteiz 


\section{Bibliografía}

\section{ARTÍCULOS E INFORMES}

Organización de las Naciones Unidas para la Alimentación y la Agricultura (FAO), 2011. El estado de los recursos de tierras y aguas del mundo.

Herrán A., Lacalle R.G., Iturritxa M. J., Martínez M., Vilela J., 2016. First results of Technosols constructed from municipal waste in Vitoria-Gasteiz (Spain). Departamento de medio ambiente y salud pública, Ayuntamiento de Vitoria-Gasteiz.

Centro de Estudios Ambientales (CEA), 2014. La infraestructura verde urbana de VitoriaGasteiz. Ayuntamiento de Vitoria-Gasteiz.

Plan Integral de Carreteras de Álava (PICA), 2009. Boletín oficial del territorio histórico de Álava. $\mathrm{N}^{\mathrm{o}} 18$. Departamento de obras públicas y transportes.

Artetxe, U. García-Plazaola, J.I. Hernández A. and Becerril J.M., 2002. Low light grown duckweed plants are more protected against the toxicity induced by $\mathrm{Zn}$ and $\mathrm{Cd}$. Plant Physiology and Biochemistry 40: 859-863.

García-Plazaola, J.I. and J.M. Becerril., 1999. A rapid HPLC method to measure lipophilic antioxidants in stressed plants: simultaneous determination of carotenoids and tocopherols. Phytochem. Anal. 10:307-313.

García-Plazaola, J.I. and J.M. Becerril. 2001., Seasonal changes in photosynthetic pigments and antioxidants in beech (Fagus sylvatica) in a Mediterranean climate: implications for tree decline diagnosis. Aust. J. Plant. Physiol. 28:225-232.

\section{INSTITUCIONES}

Organización de las Naciones Unidas para la Alimentación y la Agricultura (FAO). Consultado el 20 de abril de 2016. http://www.fao.org/

Ministerio de Agricultura, Alimentación y Medio Ambiente (MAGRAMA). http://www.magrama.gob.es/

Web del Ayuntamiento de Vitoria-Gasteiz, Restauración de suelos degradados. Consultado el 24 de abril de 2016. http://www.vitoria-gasteiz.org/we001/was/we001Action.do?idio$\mathrm{ma}=\mathrm{es} \&$ aplicacion $=\mathrm{wb} 021 \&$ tabla $=$ contenido\&uid $=\mathrm{u} \_684 \mathrm{bbe} 23 \_14 \mathrm{ddbae} 27 \mathrm{c} 8 \_7 \mathrm{f} 4 \mathrm{f} \& \mathrm{a}$ lias

\section{BLOGS}

Proyecto Tecnosuelos Gardelegi. http://tecnosuelosgardelegi.blogspot.com.es/

Proyecto de Restauración de suelos degradados en Júndiz (Vitoria-Gasteiz). http://colaboradores.vitoria-gasteiz.org/pilotojundizmaterialbioestabilizado/ 
